\title{
Dos casos de Piosalpinx Tuberculoso
}

\author{
Dr. Aristóbulo Cruz Amaya \\ Del Centro Médico del Quindío - Armenia
}

Sin pecar de exagerados podemos afirmar, que la incidencia de la tuberculosis genital en nuestro medio, es muy superior a la de los casos que diagnosticamos.

Es por esta razón que hay que pensar siempre en esta enfermedad al examinar a una paciente ginecológica, ya que su sintomatología es muy proteiforme, el diagnóstico no lo podemos hacer muchas veces ni durante la operación y solamente recibimos la sorpresa al leer el resultado del estudio histológico de la pieza extraída cuando ya nuestra conducta quirúrgica no tiene rectificaciones que eventualmente pudieran presentar una mejor terapéutica para su enfermedad.

Hago hincapié en la diversidad de síntomas con que se puede manifestar especialmente la salpingitis tuberculosa, para que frente a un caso sospechoso, con masa inflamatoria de la pelvis sin antecedentes de enfermedad ginecológica aguda, se practiquen todos los exámenes necesarios (cultivo de sangre menstrual, biopsia endometrial, eritrosedimentación, cutirreacción, estudios radiológicos cuando estén indicados, etc.) con el fin de aclarar en lo posible el diagnóstico para poder enfocar un tratamiento adecuado, que varía de acuerdo con la edad de la paciente y el grado más o menos avanzado de la enfermedad.

Al lograr el diagnóstico oportuno de una salpingitis tuberculosa en su fase miliar, se puede conseguir con el tratamiento médico un excelente resultado, no solamente para la enfermedad en sí. sino para su principal consecuencia, la esterilidad. 
En caso ae encontrar un estado móa avanzado, como el parenquimatoso, o el caseoso, se debe pensar en el tratamiento quirúrgico, que es diferente de acuerdo con la edad de la paciente y siempre acompañado de tratamiento médico pre y postoperatorio. En una enferma joven es importante salvar el útero y parte de los ovarios, auncuando pierda las trompas, con el fin de librarla de los trastornos síquicos por falta de menstruación, consideración que no hay que tener en cuenta en pacientes de edad avanzada, en las que es más aconsejable sacar útero y anexo hasta donde sea posible.

Para corroborar las anteriores afirmaciones, presento a continuación dos casos, en los cuales el diagnóstico se hizo por el estudio histológico de las piezas quirúrgicas extraídas. Sin embargo cabe anotar, que en estos dos casos, como sucede con frecuencia, se trataba de una infección secundaria añadida a la lesión tuberculosa de las trompas, lo que motivó un cuadro agudo que no dio tiempo a verificar todos los exámenes para precisar el diagnóstico, pues su estado de gravedad imponía la intervención quirúrgica de urgencia.

\section{CASO No 1}

(Historia Clínica Nọ 40.250 - Hospital San Juan de Dios. Armenia).

Paciente de 33 años de edad, ingresa al hospital el 10 de junio de 1959, por cuadro abdominal agudo, constipación pertinaz, y dolor acentuado en el bajo vientre.

La enferma relata que hace 7 meses fue operada de la matriz por "hemorragias muy frecuentes y prolongadas", y que desde entonces no volvió a tener menstruación. Dos meses después de la operación empezó a sentir dolor abdominal y apareció una supuración vaginal; un mes más tarde notó la aparición de una masa abdominal baja, acompañada de dolores que se fueron haciendo más intensos hasta que en los últimos 15 días se presentaron en forma de cólicos, con vómito, escalofrío y fiebre. Además hace 6 días que no hace deposición y siente ardor al orinar.

Al examen físico se encuentra una enferma en muy mal estado general; a la inspección se ve una cicatriz infraumbilical correspondiente a la intervención anotada; a la palpación se aprecia una tumoración en la región hipogástrica, dura, irregular, inmóvil y dolorosa.

Examen ginecológico: Espéculo: cuello erosionado, sangrante y abundante flujo purulento en la vagina. Tacto vaginal: todos los fondos de saco se en- 
cuentran ocupados por masa de consistencia dura, fija e irregular y muy dolorosa.

Exámenes de laboratorio: Hematíes 4.900.000, Leucocitos 10.800, Hemoglobina $78 \%$, Neutrófilos $56 \%$, Linfocitos $40 \%$. Orina normal. Serología negativa. Radiografía simple de abdomen: dilatación de asas delgadas. Tensión 110 x 70, pulso 108. Temperatura $38^{\circ} \mathrm{C}$.

Se trató la enferma con antibióticos de amplio espectro, soluciones electrolíticas y transfusiones, pero como no cedió el estado de gravedad, se practicó laparotomía infraumbilical y se encontró epiplón, intestino delgado y sigmoide adheridos a dos bolsas de pus que correspondían a las trompas, formando todo una masa que ocupaba toda la pelvis. Después de liberar epiplón e intestino y extraer las bolsas de pus, se comprobó que le había sido practicada una histerectomía subtotal; existían además abundantes ganglios hipertrofiados, que se enviaron a estudio histológico, el que dio como resultado LINFADENITIS TUBERCULOSA MESENTERICA. El estudio bacteriológico del pus dio estafilococo.

La enferma hizo al cuarto día postoperatorio una oclusión que obligó a reintervenir con resección de una porción de intestino delgado y murió al día siguiente.

\section{CASO $\mathbf{N}^{0} 2$}

(Historia Clínica No 48.904 - Hospital San Juan de Dios. Armenia).

Enferma de 15 años de edad, ingresó al hospital el 6 de junio de 1960, por dolor abdominal agudo, especialmente en el hipogastrio, con micciones dolorosas y frecuentes y constipación desde hace 3 días.

La enfermedad empezó hace mes y medio por discreto dolor abdominal con dificultad para la deposición, que era muy frecuente y con alguna cantidad de moco. Fue tratada con antiamibianos y desinfectantes intestinales sin lograr ninguna mejoría. Los dolores fueron aumentando en intensidad hasta que hace 3 días apareció escalofrío, fiebre, vómito, constipación pertinaz, poliuria disuria y abundante flujo blanco. El ciclo era de $30 \times 3$; última menstruación 20 días antes.

Al examen físico se encuentra una paciente en mal estado general; a la palpación abdominal se aprecia marcada defensa en el hipogastrio; al tacto rectal se encuentra toda la pelvis ocupada por una masa fluctuante, fija y dolorosa. Tensión $100 \times 60$, pulso 120 por minuto. Temperatura 39\% C.

Exámenes de laboratorio: Hematíes 3.410 .000 , Hemoglobina $65 \%$, Hematocrito $39 \%$, Leucocitos 14.000 , Polinucleares $28 \%$, Linfocitos $72 \%$, Serología normal. Protrombina $73 \%$. 
En la laparotomía infraumbilical practicada de urgencia se encontró epiplón, intestino delgado y sigmoide adosados a dos bolsas de pus, que junto con matriz y vejiga formaban una sola masa que llenaba la pelvis. Después de liberar epiplón, intestino e individualizar la matriz se comprobó que se trataba de salpingitis bilateral. Se practicó salpingectomía bilateral y se envió el material para estudio histológico cuyo diagnóstico fue de SALPINGITIS TUBERCULOSA. En el estudio bacteriológico del pus se encontró estafilococo.

El postoperatorio fue normal y salió del hospital 8 días después para continuar con tratamiento médico a base de estreptomicina y nidrazid.

\section{RESUMEN}

1 - Se llama la atención sobre el creciente aumento de casos de tuberculosis anexial al hacer un estudio más completo de cada caso y sobre la diversidad de síntomas con que pueden presentarse.

2 - En presencia de esta enfermedad la conducta es diferente según su grado más o menos avanzado y de acuerdo con la edad de las pacientes.

3 - Se presentan 2 casos que fueron intervenidos por una afección ginecológica aguda y que fueron diagnosticados como salpingitis tuberculosa al examen anatomopatológico. Ambos casos tenían además una infección secundaria por estafilococo.

\section{BIBLIOGRAFIA}

SERIF H. CANGA. The role of tuberculosis of the female genitalia in sterility. International journal of fertility. July-sept. 1958. Vol. III № 2.

DEL.LEPIANE, G. REVELLI E., and DURANDO G. The problem of sterility in genital tuberculosis of the female. Tercer Congreso Mundial de Fertilidad y Esterilidad. Amsterdam 1959.

POUS - PUIGMACIA. Hacia un nuevo síndrome en la tuberculosis genital inaparente. Barcelona. España. Tercer Congreso Mundial de Fertilidad y Fsterilidad. Amsterdam, 1959.

ARTHUR M. SUTHERLAND. Genital tuberculosis in women. American Journal of Obstetrics and Ginecology. Marzo 1960. Pág. 486. 